\title{
Lactamomethylation of Phenols: Synthesis, In Silico Study of Reactivity and Possible Applications ${ }^{\dagger}$
}

\author{
Stepan Vorobyev *, Olga Primerova and Vladimir Koshelev
}

Citation: Vorobyev, S.; Primerova, O.; Koshelev, V. Lactamomethylation of Phenols: Synthesis, In Silico Study of Reactivity and Possible Applications. Chem. Proc. 2021, 3, 81. https://doi.org/10.3390/ecsoc-2408408

Academic Editors: Julio A. Seijas and M. Pilar Vázquez-Tato

Published: 14 November 2020

Publisher's Note: MDPI stays neutral with regard to jurisdictional claims in published maps and institutional affiliations.

Copyright: (C) 2020 by the authors. Licensee MDPI, Basel, Switzerland. This article is an open access article distributed under the terms and conditions of the Creative Commons Attribution (CC BY) license (http://creativecommons.org/licenses/by/4.0/).

\author{
Department of Organic Chemistry and Petroleum Chemistry, Gubkin Russian State University of Oil and Gas, \\ Leninsky av. 65, 119991 Moscow, Russia; primerova92@yandex.ru (O.P.); koshelev.v@gubkin.ru (V.K.) \\ * Correspondence: vorstepan@yandex.ru \\ + Presented at the 24th International Electronic Conference on Synthetic Organic Chemistry, \\ 15 November-15 December 2020; Available online: https://ecsoc-24.sciforum.net/.
}

\begin{abstract}
Lactamomethylation of phenols with various substituents was provided by pyrrolidone, valerolactam, caprolactam, and 4-phenylpyrrolidone derivatives. The structures of the target compounds were confirmed by IR and NMR study. The behavior of alkylphenols (2,4-di-tert-butyl- and thymol), diphenols (catechol and hydroquinone), formylphenol (vanillin), and hydroxybenzoic acids (salicylic and resorcylic) in this reaction was compared by quantum-chemical calculations. For several compounds, the energy of dissociation of the ArO-H bond was calculated by quantumchemical method to reveal their possible antioxidant activity. In addition, the ability of synthesized compounds to destruct cumene hydroperoxide was studied. It was estimated that 1-(4-hydroxy-5isopropil-2-methylbenzyl)azepan-2-one and 1-(4-hydroxy-5-isopropil-2-methylbenzyl)pyrrolidin2-one possess the best antioxidant effect, comparable to the one of industrial additive butylated hydroxytoluene (BHT).
\end{abstract}

Keywords: organic synthesis; phenolic derivatives; lactams; quantum-chemical calculations; antioxidant activity

\section{Introduction}

The struggle against material oxidation plays an important role in the food, pharmaceutical, and oil industries. Oxidation is known to be a radical chain process that can be interrupted by antioxidants [1]. One of the best-known classes of antioxidants are phenols, especially sterically hindered alkylphenols, which demonstrate high efficiency [2-4]. Though not being sterically hindered, thymol (2-isopropyl-5-methylphenol) also possesses antioxidant and biological activity [5-8]. Previously, it has been shown that alkylphenols with heterocyclic fragments also demonstrate high antioxidant potentia [912]. In addition, heterocyclic moieties in these compounds can reveal anti-inflammatory and analgetic effects $[13,14]$.

Basing on these works, we decided to synthesize several organic compounds with such heterocyclic substituents as lactams. Lactams and their derivatives are well known for their wide spectra of biological activity, such as nootropic and neuropsychotropic activities [15,16] and anticonvulsant and anxiolytic effects $[17,18]$.

As a result, we have successfully synthesized alkylphenols derivatives (of 2,4-di-tertbutylphenol and thymol) with fragments of pyrrolidone, valerolactam, caprolactam, and 4-phenylpyrrolidone [19]. In addition, we have obtained similar compounds for polyphenolic compounds, such as catechol and hydroquinone [20], and resorcinol, pyrogallol, and phenolic acids [21].

In this work, we discuss the selectivity of the phenolic ring's substitution and some possible applications of the novel compounds. 


\section{Results and Discussion}

As mentioned above, we have synthesized [19] eight compounds (1-8, Scheme 1) according to the method proposed in the work [22]. However, we also found that decreasing the amounts of trifluoroacetic acid (TFA) used in this synthesis, in comparison to the original methods, led to the improvement of the target compounds' yields.<smiles>[R]C1CC(=O)N(Cc2cc(C(C)(C)C)cc(C(C)(C)C)c2O)C1</smiles>

$1-4$

1: $\mathrm{n}=1, \mathrm{R}=-\mathrm{H}(53 \%)$

2: $\mathrm{n}=2, \mathrm{R}=-\mathrm{H}(45 \%)$

3: $\mathrm{n}=3, \mathrm{R}=-\mathrm{H}(61 \%)$

4: $\mathrm{n}=1, \mathrm{R}=-\mathrm{Ph}(52 \%)$.<smiles>[R]C1CN(CO)C(=O)C1C</smiles><smiles>CC(C)(C)c1ccc(O)c(C(C)(C)C)c1</smiles>

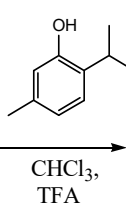

$\mathrm{HCl}_{3}$,

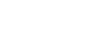<smiles>[R]C(C)CN(Cc1cc(C(C)C)c(O)cc1C)C(=O)CC</smiles>

5-8

5: $\mathrm{n}=1, \mathrm{R}=-\mathrm{H}(50 \%)$; 6: $\mathrm{n}=2, \mathrm{R}=-\mathrm{H}(44 \%)$; 7: $\mathrm{n}=3, \mathrm{R}=-\mathrm{H}(65 \%)$; 8: $n=1, R=-P h(57 \%)$.

Scheme 1. Lactamomethylation of 2,4-di-tert-butylphenol and thymol.

Target compounds were obtained with acceptable yields. Their structure was confirmed by IR and NMR study, and by elemental analysis. For the 2,4-di-tert-butylphenol, there is only one possible path of substitution due to the steric factor. However, for thymol, there are two expected methods of substitution - in ortho or para - positions (the sixth and the fourth ones, respectively, in the stated compound) to the hydroxyl group. For compound 5 there are two peaks observed $(6.70$ and $6.96 \mathrm{ppm})$ of aromatic protons in the ${ }^{1} \mathrm{H}$-spectrum (Figure 1); both of them are singlets, which indicates that the para-substitution took place (otherwise, the AB-system of doublets should be expected). The same multiplicity of aromatic protons' signals reveals the same reaction's path for the other thymol derivatives 6-8.

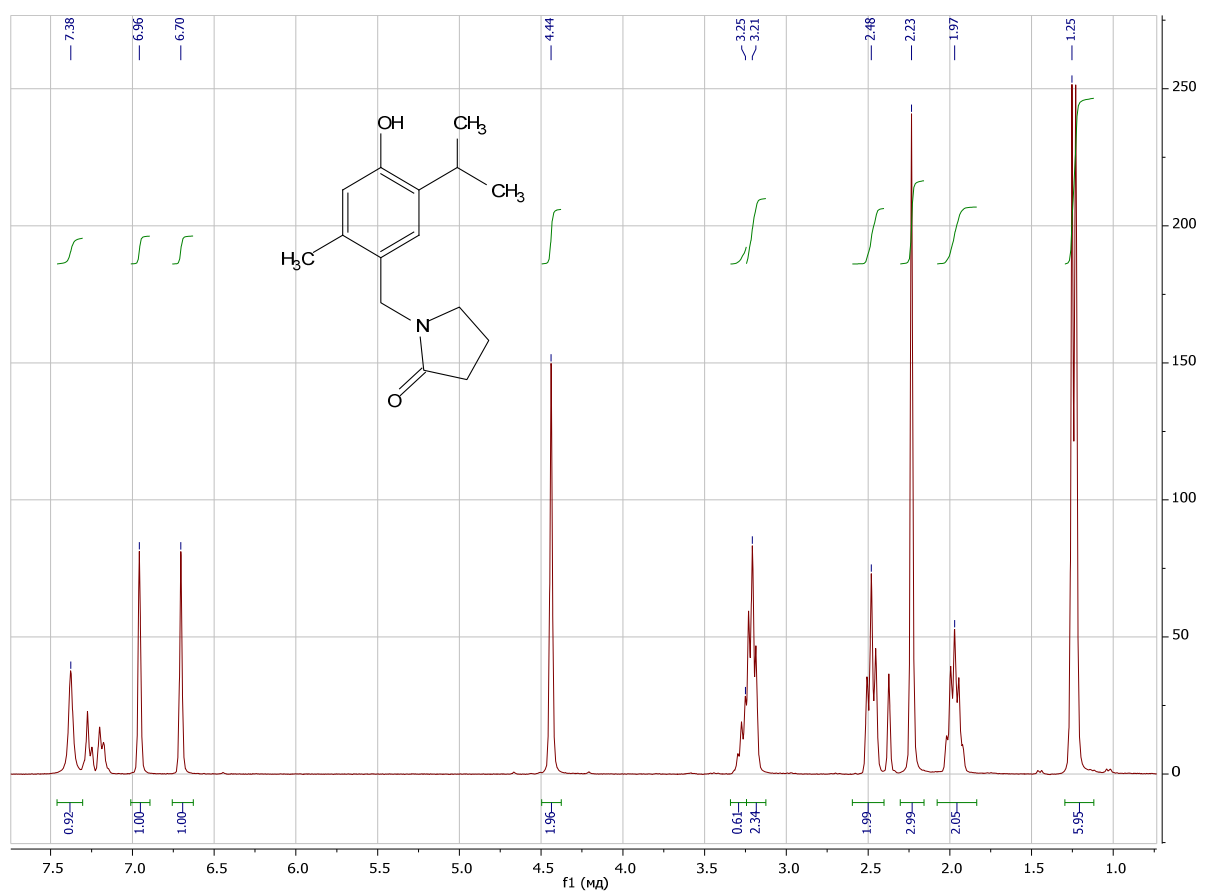

Figure 1. ${ }^{1} \mathrm{H}-\mathrm{NMR}$ spectrum of compound 5. 
It is known from the literature [23,24] that thymol can form products of Mannich reaction either of ortho- or para-substitution, but there is no systematical study of the factors influencing the manner of the reaction. Only one explanation was given [24], that it depends on the structure of the aminomethyl fragment. Noteworthy is that the conditions of aminomethylation reaction were the same in this work, although various products were obtained, so we can suppose that solvation does not play an important role in the orientation of the electrophile's attack.

We decided to prove our suggestion that the manner of the reaction depends on the stability of the forming intermediate $\sigma$-complex. Thus, a stable, low-energy $\sigma$-complex results in a high reaction rate, while a high-energy $\sigma$-complex represents a low reaction rate (according to Hammond's posulate).

Quantum-chemical calculations for compound 5 showed that the complex with the electrophile, formed in the fourth position (para-), is more stable than the one in the sixth (ortho-), as its energy is $6.5 \mathrm{~kJ} / \mathrm{mol}$ lower (Scheme 2). Noteworthy is that the minimum energy for the intermediate $\mathbf{5 a}$ (for the ortho-substitution) corresponds, not to the $\sigma$-complex, but to the $\pi$-one, which does not lead to the formation of the $\sigma$-bond, and, thus, to the formation of the product. We can assume that the energy of the appropriate $\sigma$-complex is even higher. Complex $\mathbf{5 b}$ is also stabilized by an intramolecular hydrogen bond, as shown on the scheme:<smiles>Cc1ccc(C(C)C)c(O)c1</smiles>

$5 \mathbf{a}$

$\mathrm{E}=-789.373412$

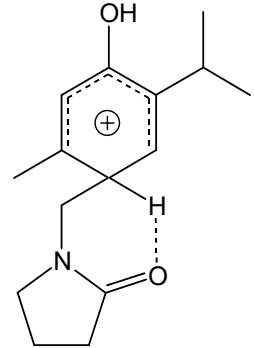

$5 \mathbf{b}$

$\mathrm{E}=-789.375873$

Scheme 2. The structure of the two possible intermediates, $5 \mathbf{a}$ and $\mathbf{5 b}$. The free energy $\Delta \mathrm{G}$ values (E, a.u.) are shown for each particle.

A similar situation is observed for a range of our compounds. Thus, for salicylic and $\beta$-resorcylic acids there are several possible isomeric products. It has been shown [21] that, in the case of these acids, the lactamomethylation reaction took place in the third position (Scheme 3).<smiles>[R]c1ccc(C(=O)O)c(O)c1</smiles><smiles>CC1C2CCCC1C(=O)N(CO)C2</smiles>

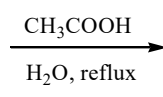<smiles>[R]c1ccc(C(=O)O)c(O)c1CN1CCCC1</smiles>

9: $\mathrm{R}=-\mathrm{H}, \mathrm{n}=1(48 \%)$

10: $\mathrm{R}=-\mathrm{OH}, \mathrm{n}=1(62 \%)$;

11: $\mathrm{R}=-\mathrm{OH}, \mathrm{n}=3(41 \%)$.

Scheme 3. Lactamomethylation of salicylic and resorcylic acids.

As expected, the quantum-chemical calculations are in agreement with the experimental data (Scheme 4). For the salicylic acid complex, electrophile in the third position is more preferable than one in the fifth, as the latter has energy that is $6.5 \mathrm{~kJ} / \mathrm{mol}$ higher. In 
the case of resorcylic acid, the difference in energies is even more significant, as the complex in the third position has energy that is $16.2 \mathrm{~kJ} / \mathrm{mol}$ lower than other possible isomer.

Both acids form hydrogen bonds in the case of substitution in the third position, as can be seen on the scheme:<smiles>O=C1O[C@H]2CCCN(Cc3cccc1c3O)C(=O)O2</smiles>

9a $E=-820.792221$<smiles>CCCN1Cc2c(O)ccc(c2O)C(=O)O[Hg]OC1=O</smiles>

$10 \mathrm{a}$

$\mathrm{E}=-896.025973$<smiles>O=C(O)c1cc(CN2CCCC2=O)ccc1O</smiles>

$9 \mathbf{b}$

Scheme 4. The structure of the pairs of possible intermediates $9 a$ and $9 \mathbf{b}, \mathbf{1 0 a}$ and $\mathbf{1 0 b}$. The free energy $\Delta G$ values (E, a.u.) are shown for each particle.

The same observations were made for catechol derivatives [20] (Scheme 5). The hydrogens in intermediate 11a form strong hydrogen bonds with nearby oxygens. This decreases the energy, and this intermediate is more stable, as its energy gain is equal to 60.1 $\mathrm{kJ} / \mathrm{mol}$.<smiles>O=C1CCCN1Cc1cccc2c1OCO2</smiles>

$11 \mathrm{a}$

$\mathrm{E}=-707.480898$<smiles></smiles>

11b

Scheme 5. The structure of the possible intermediates $\mathbf{1 1 a}$ and $\mathbf{1 1 b}$. The free energy $\Delta \mathrm{G}$ values (E, a.u.) are shown for each particle.

We also decided to predict the manner of substitution for a phenolic compound and then to provide lactamomethylation. We chose vanillin because of its commercial availability and because of the presence of several substituents in its ring. Although the fifth position was expected to be substituted by the lactamomethyl moiety, the non-cooperative 
orientational interaction of the formyl-, hydroxyl-, and methoxy-groups can give surprising result.

Quantum-chemical calculations demonstrate that the most stable is complex 12a, which is formed if the substitution in the fifth position take place (Scheme 6). Two other intermediates, 12b and 12c, both have higher energies $(24.5 \mathrm{~kJ} / \mathrm{mol}$ and $27.5 \mathrm{~kJ} / \mathrm{mol}$, respectively). The first complex is stabilized by a strong hydrogen bond (about $1 \AA$ ). In the case of intermediate $\mathbf{1 2 c}$, we can see that the energy minimum corresponds to the $\pi$-complex.<smiles></smiles>

12a<smiles>COc1cc(C=O)ccc1O</smiles>

12b<smiles>COc1cc(C=O)ccc1O</smiles>

$12 \mathrm{c}$

$E=-860.036412$

$\mathrm{E}=-860.027090$

Scheme 6 . The structure of the possible intermediates 12a, 12b, and 12c. The free energy $\Delta G$ values (E, a.u.) are shown for each particle.

We succeeded in further synthesis of several vanillin derivatives (Scheme 7). Three compounds have been obtained, and their structures were confirmed by IR and NMR investigations. In the ${ }^{1} \mathrm{H}$-spectrum of compound 13, an AB-system of doublets is observed for the aromatic protons. The value of the coupling constant (about $1.6 \mathrm{~Hz}$ ) proves that it corresponds to the protons separated with four bonds $\left({ }^{4} \mathrm{~J}\right)$.<smiles>[R]C1CN(C)C(=O)C1C</smiles>

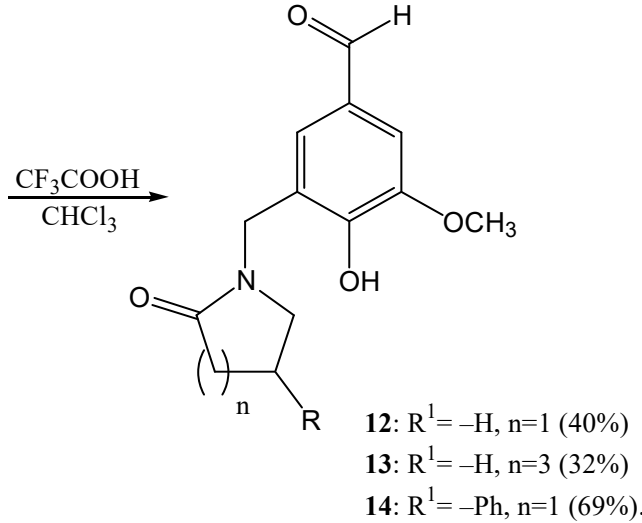

Scheme 7. Lactamomethylation of vanillin.

To demonstrate the antioxidant activity of several synthesized compounds, we primarily performed quantum-chemical calculations [19] to evaluate the dissociation energy of the ArO-H bond in the alkylphenols, according [25]. The results are shown in Table 1. 
Table 1. Dissociation energy (D) of the ArO-H bond in phenols.

\begin{tabular}{cc}
\hline Compound & D(ArO-H), $\mathbf{k c a l} / \mathbf{m o l}$ \\
\hline Thymol & 82.0 \\
2,4-di-tert-butylphenol & 82.5 \\
1 & 82.8 \\
2 & 83.2 \\
3 & 88.9 \\
4 & 82.6 \\
5 & 78.8 \\
6 & 78.5 \\
7 & 78.7 \\
8 & 78.9 \\
butylated hydroxytoluene (BHT) & 75.4 \\
\hline
\end{tabular}

The lower the energy is, the higher the antioxidant potential is, as the bond demonstrates an ability to break. As we can see, our compounds can demonstrate antioxidant activity comparable to the industrial additive butylated hydroxytoluene (BHT). These results can be proved by experimental evaluation of the antioxidant activity, which has been performed by the investigation of the ability of the target compounds to destruct cumene's hydroperoxide [26]. We found that compounds 5 and 7 demonstrate the highest antioxidant activity among the studied compounds, decreasing the concentration of hydroperoxide almost thrice in four hours. This is comparable with the result shown by BHT. These data are in agreement with the calculation results, so we can infer that this method is suitable for predicting the antioxidant activity of phenols.

\section{Materials and Methods}

\subsection{Quantum-Chemical Calculations}

All quantum-chemical calculations were performed with the help of Gaussian09 software [27]. To evaluate the stability of intermediates in the lactamomethylation reaction, the functional M06-2X was chosen with the $6-311 \mathrm{G}(\mathrm{d}, \mathrm{p})$ basic set. Gibbs energies are given in hartree units, which can be converted to $\mathrm{kJ} / \mathrm{mol}$ by multiplying them by 2625.5 . The calculations of the intermediates' stability were made only for complexes with pyrrolidone derivative in order to reduce the computation time.

Evaluation of the dissociation energy of the ArO-H bond was performed using the semi-empirical method PM6.

\subsection{Synthesis of the Target Compounds}

The reagents and solvents were commercial products (Acros, Waltham, MA, USA, and Sigma-Aldrich, St. Louis, MO, USA); 1-hydroxymethylpyrrolidin-2-one, 1-hydroxymethylazepan-2-one, and 1-hydroxymethyl-4-phenylpyrrolidin-2-one, used as the starting compounds, were synthesized as described previously $[19,20]$. The synthesis of the 2,4-di-tert-butylphenol and thymol derivatives have also been described previously [19].

The melting points were determined on a Stuart SMP30 instrument. The IR spectra were recorded on an Agilent Carry 600 spectrometer equipped with an attenuated total reflectance (ATR) device. The ${ }^{1} \mathrm{H}$ and ${ }^{13} \mathrm{C}$ NMR spectra were measured at room temperature on Bruker Avance II 300 spectrometers $\left({ }^{1} \mathrm{H}, 300 \mathrm{MHz} ;{ }^{13} \mathrm{C}, 75 \mathrm{MHz}\right)$ in $\mathrm{CDCl}_{3}$; $\mathrm{Me}_{4} \mathrm{Si}$ was used as the internal standard. Elemental analysis was performed using Vario MicroCube apparatus.

Synthesis of lactamomethyl derivatives of vanillin (general procedure). A solution of vanillin $(1.52 \mathrm{~g}, 0.01 \mathrm{~mol})$, lactamomethylating reagent (N-hydroxymethyllactam, 0.01 $\mathrm{mol})$, and trifluoroacetic acid $(8 \mathrm{~mL})$ in chloroform $(20 \mathrm{~mL})$ was refluxed for $48 \mathrm{~h}$. Then 
the reaction mixture was cooled and poured into toluene $(75 \mathrm{~mL})$. The resulting solution was washed with an aqueous sodium bicarbonate solution to neutral $\mathrm{pH}$. The organic layer was separated using a separatory funnel, dried over calcinated magnesium sulfate, and was then rotary evaporated. The residue was dissolved in ethylacetate, and the product was isolated by column chromatography (eluent ethylacetate or the mixture of ethylacetate:hexane $=2: 1$ ). Eluent was rotary evaporated, and the crude product was filtered off and recrystallized from acetonitrile.

\subsubsection{4-Hydroxy-3-Methoxy-5-[(2-Oxopyrrolidin-1-yl)Methyl]Benzaldehyde $\mathbf{1 2}$}

After column chromatography (ethylacetate) on silicagel, $1.01 \mathrm{~g}(40 \%)$ of brown crystals was obtained. M.p. $144^{\circ} \mathrm{C}$ (acetonitrile). IR v/cm ${ }^{-1}: 1686,1650(\mathrm{C}=\mathrm{O})$.

${ }^{1} \mathrm{H}$ NMR $\left(\mathrm{CDCl}_{3}, \delta, \mathrm{ppm},{ }^{3} \mathrm{JHH}, \mathrm{Hz}\right): 1.92\left(\mathrm{p}, 2 \mathrm{H}, 4-\mathrm{CH}_{2}\right.$ in lactam, $\left.J=7.45\right) ; 2.28(\mathrm{t}, 2 \mathrm{H}$, 3-CH2 in lactam, $J=8.20) ; 3.28(\mathrm{t}, 2 \mathrm{H}, 5-\mathrm{CH} 2$ in lactam, $J=6.71) ; 3.87\left(\mathrm{~s}, 3 \mathrm{H}, \mathrm{OCH}_{3}\right) ; 4.37$ (s, 2H, $\left.\mathrm{ArCH}_{2}\right) ; 7.28$ (s, 1H, Ar); 7.36 (s, 1H, Ar); 9.77 (bs, 1H, OH); 10.09 (bs, 1H, -CHO).

${ }^{13} \mathrm{C} \mathrm{NMR}\left(\mathrm{CDCl}_{3}, \delta, \mathrm{ppm}\right): 17.94\left(4-\mathrm{CH}_{2}\right.$ in lactam); $30.69\left(\mathrm{C}(\mathrm{O}) \mathrm{CH}_{2}\right) ; 40.94\left(\mathrm{ArCH}_{2} \mathrm{~N}\right) ;$ $47.22\left(\mathrm{NCH}_{2}\right.$ in lactam); $56.46\left(\mathrm{ArO}_{\mathrm{CH}}\right) ; 110.16 ; 124.26 ; 125.58 ; 128.57 ; 148.44 ; 151.10$ (6 Ar); 174.90; 191.68 (2 C=O).

Calc., \%: C 62.64, H 6.07, N 5.62. Found, \%: C 61.10, H 6.00, N 5.45. $\mathrm{C}_{13} \mathrm{H}_{15} \mathrm{NO}_{4}$.

\subsubsection{4-Hydroxy-3-Methoxy-5-[(2-Oxoazepan-1-yl)Methyl]Benzaldehyde 13}

After column chromatography (ethylacetate:hexane $=2: 1$ ) on silicagel, $0.89 \mathrm{~g}(32 \%)$ of white powder was obtained. M.p. $113^{\circ} \mathrm{C}$ (acetonitrile). IR v/cm-1: 1678, 1601 (C=O).

${ }^{1} \mathrm{H}$ NMR $\left(\mathrm{CDCl}_{3}, \delta, \mathrm{ppm},{ }^{3} \mathrm{~J} \mathrm{HH}, \mathrm{Hz}\right): 1.48-1.70\left(\mathrm{~m}, 6 \mathrm{H}, 4,5,6-\mathrm{CH}_{2}\right.$ in lactam); $2.51(\mathrm{~m}$, $2 \mathrm{H}, 3-\mathrm{CH}_{2}$ in lactam); 3.40 (m, 2H, 7- $\mathrm{CH}_{2}$ in lactam); $3.87\left(\mathrm{~s}, 3 \mathrm{H}, \mathrm{OCH}_{3}\right) ; 4.46\left(\mathrm{~s}, 2 \mathrm{H}, \mathrm{ArCH}_{2}\right)$; $7.25\left(\mathrm{~d}, 1 \mathrm{H},{ }^{4} \mathrm{~J} \mathrm{HH}=1.68, \mathrm{Ar}\right) ; 7.31\left(\mathrm{~d}, 1 \mathrm{H},{ }^{4} \mathrm{JHH}=1.68, \mathrm{Ar}\right) ; 9.73(\mathrm{bs}, 1 \mathrm{H}, \mathrm{OH}) ; 10.33(\mathrm{bs}, 1 \mathrm{H}$, $\mathrm{COH})$.

${ }^{13} \mathrm{C} \mathrm{NMR}\left(\mathrm{CDCl}_{3}, \delta, \mathrm{ppm}\right): 22.98 ; 27.61 ; 29.74 ; 36.36 ; 48.97\left(\mathrm{ArCH}_{2} \mathrm{~N}\right) ; 50.11\left(\mathrm{NCH}_{2}\right.$ in lactam); $56.16\left(\mathrm{ArOCH}_{3}\right) ; 110.81 ; 123.13 ; 127.20 ; 128.44 ; 149.47 ; 152.19$ (6 Ar); $178.51 ; 190.54$ $(2 \mathrm{C}=\mathrm{O})$.

Calc., \%: C 60.97, H 6.91, N 5.05. Found, \%: C 60.79, H 7.039, N 4.68. $\mathrm{C}_{15} \mathrm{H}_{19} \mathrm{NO}_{4}$.

3.2.3. 4-Hydroxy-3-Methoxy-5-[(2-oxo-4-Phenylpyrrolidin-1-yl)Methyl]Benzaldehyde 14

After column chromatography (ethylacetate:hexane $=2: 1)$ on silicagel, $2.26 \mathrm{~g}(69 \%)$ of yellow powder was obtained. M.p. $148^{\circ} \mathrm{C}$ (acetonitrile). IR v/cm ${ }^{-1}: 1662,1591$.

${ }^{1} \mathrm{H} \mathrm{NMR}\left(\mathrm{CDCl}_{3}, \mathrm{\delta}, \mathrm{ppm},{ }^{3} \mathrm{JHH}, \mathrm{Hz}\right): 2.59-2.93$ (AB-system of doublets with ${ }^{2} \mathrm{~J} \mathrm{HH}=17.02$, in which each line gives a doublet because of coupling ${ }^{3} \mathrm{JHH}=8.97,2 \mathrm{H}, 3-\mathrm{C} \mathrm{CH}_{2}$ in lactam); 3.42-3.86 (m, 3H, 4,5-C in lactam); $3.95\left(\mathrm{~s}, 3 \mathrm{H}, \mathrm{OCH}_{3}\right) ; 4.55\left(\mathrm{~s}, 2 \mathrm{H}, \mathrm{ArCH}_{2}\right) ; 7.15-7.38(\mathrm{~m}$, $7 \mathrm{H}, \mathrm{Ar}) ; 8.51$ (bs, $1 \mathrm{H}, \mathrm{OH}) ; 9.79$ (bs, $1 \mathrm{H},-\mathrm{CHO})$.

${ }^{13} \mathrm{C} \mathrm{NMR}\left(\mathrm{CDCl}_{3}, \delta, \mathrm{ppm}\right): 37.38\left(4-\mathrm{CH}_{2}\right.$ in lactam); $38.40\left(\mathrm{C}(\mathrm{O}) \underline{\mathrm{CH}_{2}}\right) ; 42.17\left(\mathrm{ArCH}_{2} \mathrm{~N}\right)$; $54.79\left(\mathrm{NCH}_{2}\right.$ in lactam $) ; 56.26\left(\mathrm{ArOCH}_{3}\right) ; 109.66 ; 122.33 ; 126.62 ; 127.24 ; 127.42 ; 128.92 ;$ 129.02; 141.73; 148.69; 150.97 (12 Ar); 175.24; 190.53 (2 C=O).

Calc., \%: C 70.14, H 5.89, N 4.31. Found, \%: C 69.54, H 6.431, N 4.29. $\mathrm{C}_{19} \mathrm{H}_{19} \mathrm{NO}_{4}$.

\section{Conclusions}

The ability to predict the possible reaction's method of electrophilic substitution of phenols by quantum-chemical calculations has been shown. The accuracy of the described method was confirmed by the synthesis of three novel vanillin derivatives. Their structures were investigated by IR and NMR analyses. Additionally, we have demonstrated that quantum-chemical calculations are suitable for prediction of the antioxidant activity of the phenolic compounds, as experimental data, obtained from the test on destruction of cumene's hydroperoxide, were in agreement with the calculation results. 


\begin{abstract}
Author Contributions: S.V.; concept, performing chemical synthesis and purification, spectroscopy experiments and quantum-chemical calculations, analyzing spectroscopy data, writing manuscript. O.P.; performing antioxidant activity experiment, analyzing data. V.K.; concept, supervision, writing manuscript. All authors have read and agreed to the published version of the manuscript.
\end{abstract}

Funding: This research received no external funding.

Institutional Review Board Statement: Not applicable.

Informed Consent Statement: Not applicable.

Data Availability Statement: Supplementary data (e.g., NMR spectra) are available on request from the corresponding author.

Conflicts of Interest: The authors declare no conflict of interest.

\title{
References
}

1. Burton, G.W.; Ingold, K.U. Autoxidation of biological molecules. 1. Antioxidant activity of vitamin E and related chain-breaking phenolic antioxidants in vitro. J. Am. Chem. Soc. 1981, 103, 6472-6477, doi:10.1021/ja00411a035.

2. Yehye, W.A.; Rahman, N.A.; Ariffin, A.; Hamid, S.B.A.; Alhadi, A.A.; Kadir, F.A.; Yaeghoobi, M. Understanding the chemistry behind the antioxidant activities of butylated hydroxytoluene (BHT): A review. Eur. J. Med. Chem. 2015, 101, 295-312, doi:10.1016/j.ejmech.2015.06.026.

3. Yagunov, S.E.; Kholshin, S.V. One-stage synthesis of 4-[(dodecylselanyl)methyl]-2,6-dimethylphenol based on the tandem reaction between 2,6-dimethylphenol, formaldehyde, and dodecaneselenol. Russ. Chem. Bull. Int. Ed. 2019, 68, 1125-1126, doi:10.1007/s11172-019-2530-3.

4. Wang, W.; Kannan, P.; Xue, J.; Kannan, K. Synthetic phenolic antioxidants, including butylated hydroxytoluene (BHT), in resinbased dental sealants. Environ. Res. 2016, 151, 339-343, doi:10.1016/j.envres.2016.07.042.

5. Filoche, S.K.; Soma, K.; Sissons, C.H. Antimicrobial effects of essential oils in combination with chlorhexidine digluconate. Oral Microbiol. Immunol. 2005, 20, 221-225, doi:10.1111/j.1399-302X.2005.00216.x.

6. Nieto, G. Biological activities of three essential oils of the lamiaceae family. Medicines 2017, 4, 63, doi:10.3390/medicines4030063.

7. Hashemipour, H.; Kermanshahi, H.; Golian, A.; Veldkamp, T. Effect of thymol and carvacrol feed supplementation on performance, antioxidant enzyme activities, fatty acid composition, digestive enzyme activities, and immune response in broiler chickens. Poult. Sci. 2013, 92, 2059-2069, doi:10.3382/ps.2012-02685.

8. Alagawany, M.; Farag, M.R.; Abdelnour, S.A.; Elnesr, S.S. A review on the beneficial effect of thymol on health and production of fish. Rev. Aquac. 2021, 13, 632-641, doi:10.1111/raq.12490.

9. Osipova, V.; Antonova, N.; Berberova, N.; Poddel'skii, A.; Kudryavtsev, K. Redox properties of novel pyrrolidine derivatives containing sterically hindered phenol fragment. Russ. J. Electrochem. 2011, 47, 1119, doi:10.1134/S1023193511100156.

10. Koshelev, V.; Kelarev, V.; Belov, N. Effect of azoles and sym-triazines with hindered phenol fragments on protective properties of turbine oils. Chem. Technol. Fuels Oils 1995, 31, 26-29, doi:10.1007/BF00727660.

11. Koshelev, V.N.; Golubeva, I.A.; Klinaeva, E.V.; Kelarev, V.I. Stabilization of ecologically clean diesel fuel by means of combinations of additives. Chem. Technol. Fuels Oils 1996, 32, 189-194, doi:10.1007/BF00731842.

12. Latyuk, V.; Kelarev, V.; Koshelev, V.; Korenev, K. Sulfides of the sym-Triazine series as oil-Soluble corrosion inhibitors. Chem. Technol. Fuels Oils 2002, 38, 312-315, doi:10.1023/A:1021282614918.

13. Hidaka, T.; Hosoe, K.; Yamashita, T.; Watanabe, K.; Hiramatsu, Y.; Fujimura, H. Analgesic and anti-inflammatory activities in rats of $\alpha$-(3,5-di-t-butyl-4-hydroxybenzylidene)- $\gamma$-butyrolactone (KME-4), and its intestinal damage. J. Pharm. Pharmacol. 1986, 38, 748-753, doi:10.1111/j.2042-7158.1986.tb04483.x.

14. Katayama, K.; Shirota, H.; Kobayashi, S.; Terato, K.; Ikuta, H.; Yamatsu, I. In vitro effect of N-methoxy-3-(3, 5-ditert-butyl-4hydroxybenzylidene)-2-pyrrolidone (E-5110), a novel nonsteroidal anti-inflammatory agent, on generation of some inflammatory mediators. Agents Actions 1987, 21, 269-271, doi:10.1007/BF01966487.

15. Gouliaev, A.H.; Senning, A. Piracetam and other structurally related nootropics. Brain Res. Rev. 1994, 19, 180-222, doi:10.1016/0165-0173(94)90011-6.

16. Berestovitskaya, V.M.; Vasil'eva O.S.; Ostroglyadov, E.S.; Aleksandrova, S.M.; Tyurenkov, I.N.; Merkushenkova, O.V.; Bagmetova, V.V. Synthesis and neuropsychotropic activity of indole-containing gamma-aminobutyric acid derivatives. Pharm. Chem. J. 2018, 52, 392-396, doi:10.1007/s11094-018-1827-0.

17. Deshpande, L.; DeLorenzo, R. Mechanisms of levetiracetam in the control of status epilepticus and epilepsy. Front. Neurol. 2014, 5, 11, doi:10.3389/fneur.2014.00011.

18. Malykh, A.G.; Sadaie, M.R. Piracetam and Piracetam-Like Drugs. Drugs 2010, 70, 287-312, doi:10.2165/11319230-00000000000000 .

19. Vorobyev, S.V.; Primerova, O.V.; Koshelev, V.N.; Ivanova, L.V. Synthesis of alkylphenols lactamomethyl derivatives. Butl. Commun. 2018, 54, 124-131. (In Russian). 
20. Negrebetsky, V.V.; Vorobyev, S.V.; Kramarova, E.P.; Shipov, A.G.; Shmigol, T.A.; Baukov, Y.I.; Lagunin, A.A.; Korlyukov, A.A.; Arkhipov, D.E. Lactamomethyl derivatives of diphenols: Synthesis, structure, and potential biological activity. Russ. Chem. Bull. Int. Ed. 2018, 67, 1518-1529, doi:10.1007/s11172-018-2250-0.

21. Vorobyev, S.V.; Primerova, O.V.; Ivanova, L.V.; Ryabov, V.D.; Koshelev, V.N. Facile synthesis of phenolic derivatives, containing lactamomethyl substituents. Izv. Vyssh. Uchebn. Zaved. Khim. Khim. Tekhnol. (Russ. J. Chem. Chem. Technol.) 2019, 62, 40-48, doi:10.6060/ivkkt.20196210.5930.

22. Barry, J.; Mayeda, E.; Ross, S. The amidoalkylation of aromatic hydrocarbons. Tetrahedron 1976, 33, 369-372, doi:10.1016/00404020(77)80088-4.

23. Shen, A.-Y.; Huang, M.-H.; Liao, L.-F.; Wang, T.-S. Thymol analogues with antioxidant and L-Type calcium current inhibitory activity. Drug Dev. Res. 2005, 64, 195-202, doi:10.1002/ddr.10436.

24. Inci Gul, H.; Yamali, C.; Yasa, A.T.; Unluer, E.; Sakagami, H.; Tanc, M.; Supuran, C.T. Carbonic anhydrase inhibition and cytotoxicity studies of Mannich base derivatives of thymol. J. Enzym. Inhib. Med. Chem. 2016, 31, 1375-1380, doi:10.3109/14756366.2016.1140755.

25. Vasil'ev, R.F.; Fedorova, G.F.; Trofimov, A.V.; Kancheva, V.D.; Batovska, D.I. Antioxidant activity of chalcones: The chemiluminescence determination of the reactivity and the quantum chemical calculation of the energies and structures of reagents and intermediates. Kinet. Catal. 2010, 51, 507-515, doi:10.1134/S0023158410040087.

26. Vorobyev, S.V.; Primerova, O.V.; Ivanova, L.V.; Koshelev, V.N.; Ryabov, V.D. Synthesis and antioxidant activity of phenolic derivatives with heterocycles fragments. Proc. Gubkin Russ. State Univ. Oil Gas 2018, 3, 221-230. (In Russian).

27. Frisch, M.J.; Trucks, G.W.; Schlegel, H.B.; Scuseria, G.E.; Robb, M.A.; Cheeseman, J.R.; Scalmani, G.; Barone, V.; Mennucci, B.; Petersson, G.A.; et al. Wallingford CT.; Gaussian 09, Revision, D.01; Gaussian, Inc.: Wallingford, CT, USA, 2009. 